state, they generally have a lively expectation. A squatter, M. De Becker, who lived many years at a remote station, where the blacks were in frequent communication with him, told me he had seen many of them die with a cheerful anticipation of being soon in a "better country."

Paddington, Sydney, Australia, July II

\section{Reported Discovery of Gold in Samoa}

From a note in NATURE (vol. ix. p. 273) I am surprised to learn that Mr. Williams, H.M.'s Consul in these islands, has stated, in an official despatch to the Foreign Secretary, that gold in quartz has been found on Upolu, in a valley about three miles from the Port of Apia. The samples assayed are said to have yielded at the rate of 3,000 ozs. to the ton.

No geologist who knows Samoa will believe that gold in paying quantities has been found in this island. Still, $I$ think it right to give the following explanation of what gave rise to the above report.

A few months ago gold was said to have been found, as reported by Mr. Williams. Most people here, however, disbelieved it, thinking the report had been raised by unprincipled men for the purpose of attracting settlers and promoting the sale of land. Some believed the pretended specimens of Samoan gold had not been found in Samoa, and felt quite certain they had not been procured in the particular valley specified.

The facts of the case have been lately disclosed, since $\mathrm{Mr}$. Williams left the islands in ill health; he was therefore in ignorance of them when he wrote his despatch from Sydney in October I 873 .

The specimens of gold assayed were brought from the Thames gold diggings in New Zealand, and two or three foreign settlers here, who own land in the valley where the gold is said to have been found, raised the report in order to sell their land at a high price. They appear to have imposed upon the credulity of the Consul, who took the specimens to Sydney and had them assayed there.

Upolu, Samoa, June 2

S. J. WhitMEe

\section{Photographic Irradiation}

I SHALL be obliged if you will allow me space to state more specifically why I am not able to concur in the irradiation theory of Mr. Aitken (vol, x. p. 439). I understand from his last letter that he fully agrees with Lord Lindsay and myself as to the cause of the outer irradiation, and our only difference of opinion now lies in the amount of the inner irradiation that can be traced as due to what he has termed molecular reflection within the thickness of the collodion film. Mr. Aitken and Capt. Abney both appear to consider this as the chief cause of the inner irradiation fringe, while I am disposed to rank the irradiation arising from the optical imperfections of the instrument with which the photograph is taken; together with any irradiation that may arise in the wet plate processes from circulation in the film of fluid covering the plate-before-or as very much greater in amount than the irradiation due to dispersion within the collodion film.

We should expect that light dispersed with in the thickness of the collodion film would produce its photographic effect in all directions round the illuminated point-and that the area of action would not be affected, or certainly would not be decreased, by covering the front surface of the portions of the collodion film adjacent to the directly illuminated area with an opaque object. Indeed, if the opaque object were a good reflector, such as a bright piece of platinum foil, we might expect slightly to increase the area of photographic action due to dispersion within the film; for the light dispersed towards the front surface of the film would be in great measure reflected back into the thickness of the collodion. But, as I have shown in former letters, placing a piece of platinum foil in immediate contact with the collodion film causes the photographic image of a bright image to be sharply cut off, and no perceptible irradiation can be traced under the edge of the foil.

Again, we should expect the action of dispersed light to extend further within a thick film of collodion than within a thin film; for there would be a greater thickness of illuminated collodion, and the angle through which light could be radiated directly upon the adjacent area without suffering reflection at either surface would be increased, but I have not been able to detect any perceptible difference in the amount of irradiation of similarly exposed plates coated with four thicknesses of collodion and in those coated with but one film.
I have felt myself therefore driven to look for the cause of irradiation either in some circulation taking place within the film of liquid covering the collodion at the time of exposure, which film would be interrupted and its tension greatly altered by the contact of a solid body; or else to seek its explanation in the optical imperfections of the photographic instrument. Possibly, in the wet-plate processes, circulation within the fluid film may produce a very sensible effect. Indeed, there are phenomena which make this more than probable. When a wet-plate picture of a strong light projected upon a dark background is taken with a decided over-exposure of say ten minutes or a quarter of an hour, the inner irradiation fringe is seen to be most opaque on its outer edge; and the phenomenon is so marked that it cannot be held to be an effect of contrast. This, of course, should not be the case if the irradiation edge were due merely to the optical imperfections of the instrument. Again, in the small negatives of the eclipse of December $187 \mathrm{I}$, taken at Dodabetta and Baikul, there is a decided structure in the irradiation under the prominences : under the brightest of them it can be distinctly seen that the opacity of the irradiation fringe is greatest along lines radiating from the prominences-while along the outside, that is, furthest from the prominences, there is an arc of slightly greater intensity. The same structure is traceable in all the negatives, but it is most marked in the Baikul series, and especially in those negatives in which the prominences are most exposed, viz., on the east and west limbs, at the beginning and at the end of totality. This, of course, cannot be accounted for merely by the optical imperfection theory. Again, the little brushes mentioned in a former letter as extending under the edge of the platinum foil, cannot be accounted for without supposing that there is circulation within the liquid film. I hope on my retum to England to carry out some further experiments for determining the amount of the inner irradiation which in the wet-plate processes may be due to such circulation.

A. Cowper Ranyard

Florence

\section{Curious Rainbow}

THE unusual phenomena described by $\mathrm{Mr}$. Swettenham as having been observed by him in a rainbow in the Kyles of Bute (NATURE, vol. x. p. 398), are due, I think, to interference. If I remember rightly, he will find an explanation of the matter in "Deschanel's Natural Philosophy," by Prof. Everett.

Clifton, Bristol, Oct. r9

G. J. THOMSON

\section{Aurora}

A BRIGIT display of aurora was seen here on Friday, Oct. I6, between eight and eleven o'clock. At ten o'clock, when I first saw it, the arch of the aurora stretched from Pollux to Arcturus, then both near the horizon, the apex of the arch being under Ursa Major. Deep fringes of light hung from the inner side of the arch and moved with a curtain-like motion to the north. The light was white. On Saturday night numerous streamers were seen darting upwards from the horizon; and many falling stars, two of them leaving trains of light for about a second.

Castletown, Caithness, N.B. JAMES S. ANDERSON

\section{Sneezing in Animals}

I HAVE a rough-coated terrier dog which will sneeze when told to do so. I taught him this trick by repeatedly imitating sneezing in his presence.

When about to perform, he shakes his head obliquely once or twice, just as many people do, and then ends with a good sharp sneeze. J. F. M. H. S.

\section{THE RECENT ERUPTION OF ETNA.}

PROF. ORAZIO SILVESTRI has published* his observations on the eruption of Etna which occurred on the 29th of August, and reminds us that two months previously he predicted not only the formation of the fissure on the Mongibello side, but likewise the eruption by which it was accompanied.

After an uninterrupted period of eruptive phenomena by which the central crater was considerably modified, at * "Notizie sulla eruzione dell' Etna del 29 Agosto 1874." Catania, 1874. 